\title{
The application of Facebook for informal educational purposes by management students
}

\section{Marcin Komańda}

\begin{abstract}
Social media are perceived as a phenomenon that have changed the nature of interpersonal relationships and the information flow. Education is one of possible applications of social media. The aim of this work is to present the opinion of students of management concerning the application of relationships established on Facebook as informal support in the didactic process at university.
\end{abstract}

For this purpose to be achieved 98 respondents who are students of the Faculty of Management at University of Economics in Katowice (Poland) were selected with the use of purposive sampling. The respondents expressed their opinion about the usefulness of exchange of information (in three possible forms of contact on Facebook: closed groups, open groups, and direct contact out of groups) to make it possible to discuss general issues related to problems connected with educational process at university, find out significant facts regarding the subjects/lecturers, and exchange didactic materials.

In the opinion of the respondents the lowest means for the purposes of information exchange were indicated for the form of contact within open groups. The highest standard deviations on a Likert scale are also observed in this case. Analysis of Variance (ANOVA) made it also possible to state that there are statistically significant differences of average values of the respondents' indications distinguished on the grounds of their sex for the purposes of direct contact in case of exchange of information regarding the subjects/lecturers and didactic materials.

\section{Introduction}

The prevalence of IT solutions, including especially those connected with telecommunication and access to information, makes the society perceive this technology as something natural. Not only does it translate into human behaviour in the individual dimension, but also into available procedures and solutions in the institutional dimension (Komańda, 2012). However, among researchers one may more and more often come across the key question how IT tools can be harnessed in daily routines. Education, in a broad sense, including higher education, is one of such possible areas of harnessing them (Baciu, Opre, \& Riley, 2016). Every now and again it is also stated that it is almost impossible to imagine the education process without the use of IT solutions (Blankenship, 2011).

Technologies related to social media are becoming a significant issue in the presented context. Firstly, these technologies are connected with available applications on stationary and portable devices. Secondly, the process of education is at their core. The undertaken activities harnessing social media are characterised by their participants' engagement in sharing 
existing and creating new information resources (Davis III, Deil-Amen, Rios-Aguilar, \& Canche, 2012).

The presented results of the analysis of the content of scientific articles on the use of social media in education indicate that the most common premises for the application of social media from this perspective are: improvement of the results of learning, attitudes manifested by students, or development of particular skills. It is also pointed out that teachers face the challenge of proper application of such solutions, which are frequently of innovative nature, in the didactic process (Cheston, Flickinger, \& Chisolm, 2013). This innovativeness may result, above all, from the possibility to use mobile devices and social media applications for creating opportunities for making interactions, collaboration in the conditions of continuous access to the Internet and social media themselves (Gikas, \& Grant, 2013). For this reason the application of social media is connected with their engagement in the didactic process both in classrooms during planned classes as well as out of them, in their free time (Moran, eaman, \& Tinti-Kane, 2011).

At the same time, it should be stipulated that while applying social media academic teachers, for the purposes of mobilising and engaging students in the content presented within the framework of their subject, frequently limit themselves to, above all, several forms of their application which are mostly connected with data reporting or content analysis (Tess, 2013). The generation of current students, however, seems to be interested in a broader and more diverse use of social media in the didactic process. It is pointed out that students manifest the tendency for multi-tasking, or the ability to use various types of social media parallelly at the same time (Selwyn, 2012).

\section{Experiences in the application of Facebook in the didactic process}

The results of studies concerning the application of Facebook in the didactic processes reveal that this issue is related to all problems characteristic for the use of social media. It should also be mentioned that the appropriate course of education with the use of this medium sets particular challenges of an institutional, pedagogical, or cultural nature (Manca, \& Ranieri, 2013) for both teachers and students (Gray, Annabell, \& Kennedy, 2010).

From the perspective of problems related to the use of Facebook for didactic purposes which teachers have to face one should mention the teachers' insufficient engagement in the preparation of the whole educational process and harnessing its whole potential, including available tools for conducting classes (Wang, Woo, Quek, Yang, \& Liu, 2012). There is also a very practical problem concerning the management of the students' access to the conducted course (Fewkes, \& McCabe, 2012), or the students' impression related to a badly structured course and discussions led within its framework (Wang, Woo, Quek, Yang, \& Liu, 2012).

While analysing the challenges of participation in the didactic courses from the students' perspective, one should, above all, mention one key problem, namely the use of this medium for the purposes of building and maintaining social relationships (Madge, Meek, Wellens, \& Hooley, 2009). There is a challenge of incorporating live interactions between Facebook's users (in this particular case they are students) into the didactic process in a way in which they 
would not dominate its course. The second key issue, however, is related to students' fears concerning keeping their privacy in social media (Wang, Woo, Quek, Yang, \& Liu, 2012), which may translate into their reluctance to undertake any activity in such didactic courses as well as into their engagement level.

Among general observations which one may come across in the source literature one may mention these which indicate that courses conducted with the use of Facebook may propagate group and joint learning. However, in this case the ways of achieving the desired didactic objectives should be reflected upon (Irwin, Ball, Desbrow, \& Leveritt, 2012). Facebook may be used as an educational tool which strengthens the role of communication, interaction and active participation of course members, which may in turn translate into better results of learning as well as greater satisfaction from general educational process at the university (Jenny, Lin, Wei-Chieh, \& Emily, 2013). The examples connected with engagement of people from the outside in the didactic process conducted with the use of Facebook which may assume the role of experts and bring practical aspects of the problems discussed during the courses closer to students are also invoked (Cain, Policastri, 2011). It should also be remembered that among the results of studies on the application of Facebook in the formal didactic process, there is also an issue of informal learning of students with the use of this medium with social interactions at its core (Madge, Meek, Wellens, \& Hooley, 2009).

\section{Methodology}

The main research intention was to determine the usefulness of particular communication channels available for Facebook for the selected issues related to studying. The group of respondents consisted of students of bachelor studies at the department of management at the University of Economics in Katowice. It should be emphasized that the subject of the analysis were informal relationships between students that were present in this social medium. It was done deliberately since the foregoing literature which addressed the use of Facebook in the didactic process placed the most emphasis on the courses organised in a formal way, and only the aspects of informal relationships and informal communication being the side effects of the application of this medium were taken into consideration. With regard to the presented intention and on the basis of conversations with students it was possible to identify three main communication channels used by them within this social medium as well as three main areas of the students' interests connected with the informal way of communication. Among the communication channels the following ones were distinguished: closed groups, open groups and individual, direct contact between Facebook's users. The areas of interest which conditioned the informal course of communication for educational purposes were: general issues related to the organisation of studies, exchange of information regarding lecturers and their subjects, and exchange of didactic materials.

A survey questionnaire (computerized self-administered questionnaires - CSAQ) was used in the proper study. In the questionnaire the respondents were requested to express their opinion about the usefulness and use of a particular type of communication channel for a given area of interest (the respondents gave answers in accordance with the 5-point Likert scale). 
Table 1. Numeric codes for the variables

\begin{tabular}{|c|c|c|c|}
\hline Variables & $\begin{array}{l}\text { General issues } \\
\text { related to studying }\end{array}$ & $\begin{array}{l}\text { Exchange of } \\
\text { information about } \\
\text { lecturers/subjects }\end{array}$ & $\begin{array}{l}\text { Exchange of didactic } \\
\text { materials }\end{array}$ \\
\hline Closed groups & 1 & 4 & 7 \\
\hline Open groups & 2 & 5 & 8 \\
\hline Individual contact & 3 & 6 & 9 \\
\hline
\end{tabular}

Altogether 98 people out of students of bachelor studies at the department of management at the University of Economics in Katowice took part in the study. The selection of respondents was deliberate and conditioned by prior arrangements of the subject of the study and its situational context. The respondents were aged 20-29, and as much as $95.9 \%$ of them were aged $20-24.64 .3 \%$ of the respondents were women, whereas the percentage of men amounted to $35.7 \%$.

\section{Results}

The analysis of reliability of the respondents' indications was conducted. The Cronbach's alpha coefficient amounted to 0.69. Simultaneously, the exclusion of any of the variables would not allow the level of reliability to be increased. The obtained Cronbach's alpha value is below the threshold value which can be regarded as satisfactory (0.7), however, due to the exploratory nature of the study it may serve as the basis for presenting the results of the study (Dyduch, 2015).

The hierarchical cluster analysis of variables revealed that the variables connected with the assessment of usefulness of application of communication within open groups for all three areas of interest constitute a separate cluster.

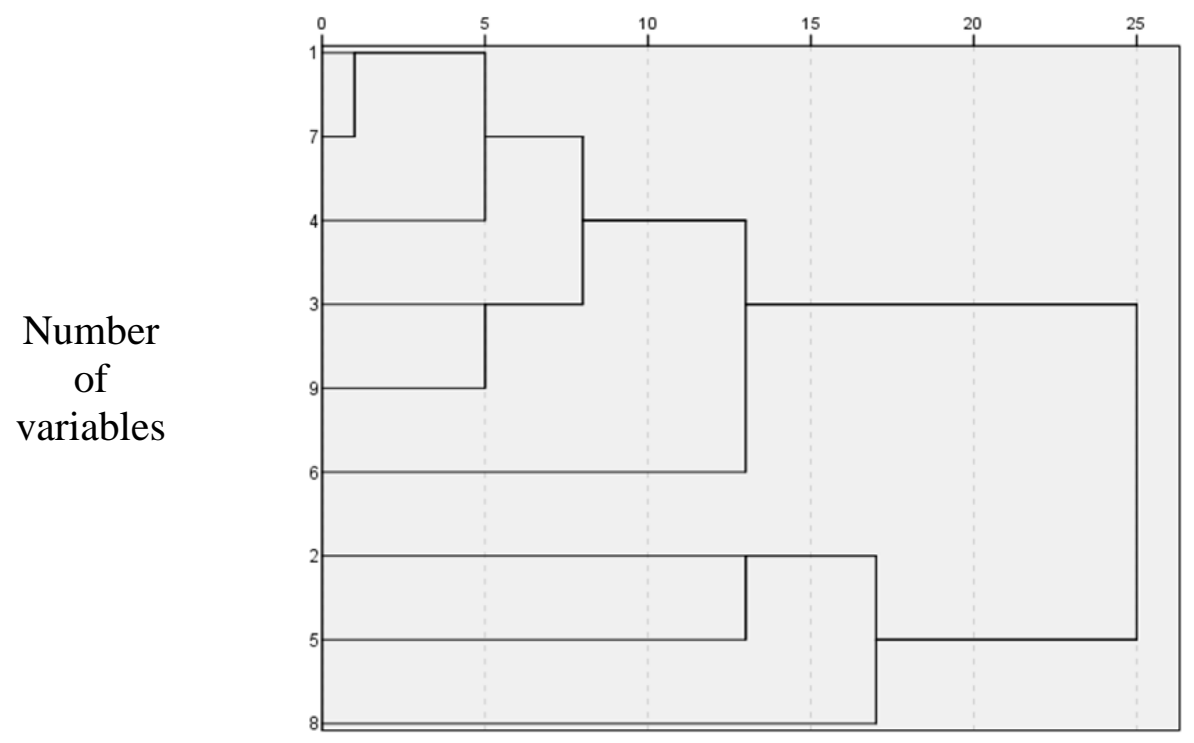

Figure 1. Dendrogram with the use of a medium link between the variables 
The reasons for such grouping may be searched for among the facts that three variables related to the use of communication of open groups on Facebook, contrary to other variables, had dominants and medians which equal to 4 (the other variables equal 5), and their means ranged from 3.77 to 3.99 , whereas the values for other variables ranged from 4.26 to 4.77 .

The gathered data underwent also the ANOVA. The analysis made it possible to state that there are statistically significant differences of mean values of the respondents' indications distinguished with regard to their sex for the purposes of assessment of usefulness of the direct contact in case of exchange of information about subjects/lecturers and didactic materials. The analysis did not make it possible to determine statistically significant differences in case of the application of closed and open groups for these purposes.

Table 2. Results of Anova

\begin{tabular}{|c|c|c|c|c|c|c|}
\hline \multicolumn{2}{|c|}{ Variable } & \multirow{2}{*}{$\begin{array}{r}\text { Sum of Squares } \\
1,080\end{array}$} & \multirow{2}{*}{$\frac{\mathrm{df}}{1}$} & \multirow{2}{*}{$\begin{array}{r}\text { Mean Square } \\
1,080\end{array}$} & \multirow{2}{*}{$\frac{F}{2,444}$} & \multirow{2}{*}{$\begin{array}{l}\text { Sig. } \\
, 121\end{array}$} \\
\hline 3 & Between Groups & & & & & \\
\hline & Within Groups & 42,400 & 96 & ,442 & & \\
\hline & Total & 43,480 & 97 & & & \\
\hline \multirow[t]{3}{*}{6} & Between Groups & 4,508 & 1 & 4,508 & 5,686 &, 019 \\
\hline & Within Groups & 76,114 & 96 & ,793 & & \\
\hline & Total & 80,622 & 97 & & & \\
\hline \multirow[t]{3}{*}{9} & Between Groups & 4,637 & 1 & 4,637 & 9,198 &, 003 \\
\hline & Within Groups & 48,394 & 96 &, 504 & & \\
\hline & Total & 53,031 & 97 & & & \\
\hline
\end{tabular}

In case of the assessment of usefulness of the individual contact for the purposes of exchange of information about lecturers and their subjects, $85.71 \%$ of men agreed that they are at least useful, whereas the percentage of women of the same opinion amounted to $73.01 \%$. As far as the acknowledgment of usefulness of individual contact via Facebook for the purposes of exchange of didactic materials is concerned, as much as $100 \%$ of men agreed that it is at least "rather useful" ( $91.43 \%$ of them stated that it is "useful"). Among women these indications constituted $90.47 \%(61.9 \%)$ respectively.

\section{Discussion}

The lower mean of respondents' indications for the assessment of usefulness of the communication channel, namely open groups, is related to relatively high values of the variance. The variance for variable 2 equals 0.99 , for variable 5 it amounts to 1.167 , whereas for variable 8 it equals 1.598 . The values of the variance for the remaining variables range from 0.571-0.909. It is worth noticing that in case of variables 2,5,8 the variance increases together with the indications for particular aspects of the informal process of education, that is exchange of information about lecturers and their subjects and exchange of didactic materials. 
It may be stated that distinguishing this group of variables in the conducted clustering procedure may be the result of students' worries concerning keeping their privacy and anonymity of expressing opinions, and finally the willingness to publicly disseminate didactic materials they possess.

The statistically significant diversity of average values for the respondents' indications with regard to their sex for variables 6 and 9 may, in turn, have a cultural background. From the observations resulting from experience in conducting classes at the university the author of this paper may refer to the general noticing of the problem of differentiation of the students' engagement level in e.g. preparation of materials from the classes, as well as students' attendance at classes with regard to sex. Women seem to be more dutiful when it comes to fulfilment of duties related to studying. It may result in further need of people who happened to miss the classes, did not prepare for them or showed no interest in the course of didactic classes to obtain didactic materials. The exchange of information about subjects and lecturers, in turn, lets students choose less demanding didactic classes or meet the lecturer's minimal expectations. In both cases the contacts of individual nature may be, as it seems, of importance for the assessment of significance of gathered information, the efficiency of gathering it, as well as trust in the reliability of didactic materials.

\section{Conclusions}

The analysis of the collected empirical material is connected with significant limitations. Firstly, the nonprobability sampling of the respondents makes it impossible to make any generalisations on a broader spectrum of students. Secondly, the structure of the respondents' group is characterised by over-representation of women which may also influence the obtained results, especially in case of the statistical significance of differentiation between average values of the respondents' indications with regard to their sex.

However, the obtained results may suggest the choice of future research areas. On the one hand, it may be stated that the use of social media for informal communication for educational purposes out of formally organised courses is a fact which deserves serious approach on the part of researchers in the field of education. On the other hand, the issue seems to be strongly connected with the socio-cultural context, the complexity, and time and place contextuality of which requires a detailed description.

\section{References}

Baciu, C., Opre, D., \& Riley, S. (2016). A New Way of Thinking in the Era of Virtual Reality and Artificial Intelligence. Educatia, 21(14), 43-48.

Blankenship, M. (2011). How social media can and should impact higher education. The Education Digest, 76(7), 39-42.

Cain, J., \& Policastri, A. (2011). Using Facebook as an informal learning environment. American Journal of Pharmaceutical Education, 75(10). DOI: 207. 10.5688/ajpe7510207. 
Cheston, C. C., Flickinger, T. E., \& Chisolm, M. S. (2013). Social media use in medical education: a systematic review. Academic Medicine, 88(6), 893-901. DOI: 10.1097/ACM.0b013e31828ffc23

Davis III, C. H., Deil-Amen, R., Rios-Aguilar, C., \& Canche, M. S. G. (2012). Social Media in Higher Education: A literature review and research directions. Retrieved from: file://C:/Users/asus/AppData/Local/Temp/fulltext_stamped.pdf

Dyduch, W. (2015). Ilościowe badanie i operacjonalizacja zjawisk w naukach o zarządzaniu. In W. Czakon (Ed.), Podstawy metodologii badań w naukach o zarządzaniu (pp. 306-331), Warszawa: Wolters Kluwer S.A.

Fewkes, A. M., \& McCabe, M. (2012). Facebook: Learning tool or distraction?. Journal of Digital Learning in Teacher Education, 28(3), 92-98. DOI: http://dx.doi.org/10.1080/21532974.2012.10784686

Gikas, J., \& Grant, M. M. (2013). Mobile computing devices in higher education: Student perspectives on learning with cellphones, smartphones \& social media. The Internet and Higher Education, 19, 18-26. DOI: http://dx.doi.org/10.1016/j.iheduc.2013.06.002

Gray, K., Annabell, L., \& Kennedy, G. (2010). Medical students' use of Facebook to support learning: Insights from four case studies. Medical Teacher, 32(12), 971-976. DOI: http://dx.doi.org/10.3109/0142159X.2010.497826

Irwin, C., Ball, L., Desbrow, B., \& Leveritt, M. (2012). Students' perceptions of using Facebook as an interactive learning resource at university. Australasian Journal of Educational Technology, 28(7), 1221-1232. DOI: https://doi.org/10.14742/ajet.798

Jenny, W. A. N. G., Lin, C. F. C., Wei-Chieh, W. Y., \& Emily, W. U. (2013). Meaningful engagement in Facebook learning environments: Merging social and academic lives. Turkish Online Journal of Distance Education, 14(1). 302-322

Komańda, M. (2012). Relacja klient-instytucja publiczna w cyberprzestrzeni, „Zeszyty Naukowe Uniwersytetu Szczecińskiego", 703, 401-407.

Madge, C., Meek, J., Wellens, J., \& Hooley, T. (2009). Facebook, social integration and informal learning at university: 'It is more for socialising and talking to friends about work than for actually doing work'. Learning, Media and Technology, 34(2), 141-155. DOI: http://dx.doi.org/10.1080/17439880902923606

Manca, S., \& Ranieri, M. (2013). Is it a tool suitable for learning? A critical review of the literature on Facebook as a technology-enhanced learning environment. Journal of Computer Assisted Learning, 29(6), 487-504. DOI: 10.1111/jcal.12007

Moran, M., Seaman, J., \& Tinti-Kane, H. (2011). Teaching, Learning, and Sharing: How Today's Higher Education Faculty Use Social Media. Babson Survey Research Group. Retrieved from: http://files.eric.ed.gov/fulltext/ED535130.pdf 
Selwyn, N. (2012). Social media in higher education. Retrieved from: http://sites.jmu.edu/flippEDout/files/2013/04/sample-essay-selwyn.pdf

Tess, P. A. (2013). The role of social media in higher education classes (real and virtual)-A literature review. Computers in Human Behavior, 29(5), A60-A68. DOI: http://dx.doi.org/10.1016/j.chb.2012.12.032

Wang, Q., Woo, H. L., Quek, C. L., Yang, Y., \& Liu, M. (2012). Using the Facebook group as a learning management system: An exploratory study. British Journal of Educational Technology, 43(3), 428-438. DOI: 10.1111/j.1467-8535.2011.01195.x 